\title{
Cognitive deterioration in association with teeth loss in elderly population: A study from Eastern India
}

\author{
Uttam Majumder ${ }^{1}$, Iti Baidya ${ }^{2}$, Avik Kumar Layek³ ${ }^{3}$ Sampa Ray Bhattacharya ${ }^{4}$, \\ Pradip Kumar Ray ${ }^{5}$ \\ ${ }^{1}$ Assistant Professor, ${ }^{3}$ Tutor, Department of Psychiatry, North Bengal Medical College, Siliguri, ${ }^{2}$ Medical Officer, \\ Department of Pathology, Bishnupur Super Speciality Hospital, Bishnupur, ${ }^{4}$ Professor and Head, Department of \\ Prosthetic Dentistry, North Bengal Dental College and Hospital, Siliguri, ${ }^{5}$ Professor and Head, Department of Dentistry, \\ Midnapore Medical College, Midnapore, West Bengal, India
}

Background: With the global increase in cognitive impairment and dementia, the need to investigate into the possible ways that can be used to prevent or delay such occurrence has been growing. Maintenance of dental care and oral hygiene has been promoted as one such aspect. Aims and Objectives: To study the association between cognitive impairment in patients without registered diagnosis of dementia with tooth loss and chewing ability. Materials and Methods: It was a cross-sectional hospital-based study where consenting elderly persons attending Dental outpatient department over 1 1 $1 / 2$ years were included. Data obtained on socio-demographic details, number of tooth loss, number of remaining teeth, subjective chewing ability, cognitive assessment as per mini-mental state examination (MMSE), and Clock Drawing Test were analyzed statistically to check correlational association. Results: In this study 96 eligible elderly persons of mean age of $68.30 \pm 6.28$ years showed increased cognitive impairment among females $(P=0.003)$, increased age $(P=0.009)$, rural background $(P=0.033)$ and low income groups $(P=0.001)$. Positive correlation was found between chewing capacity $(P=0.348)$, number of remaining teeth $(r=0.418)$ with MMSE scores. Conclusion: Our study population showed positive correlation between impaired cognition and the number of extracted tooth and chewing capacity. With further study on wider and representative population, we hope to project the role of maintaining good oral hygiene and dental care as a possible preventive strategy among many others to combat the increased burden of cognitive impairment.

Key words: Chewing ability; Cognitive impairment; Elderly; Mini-mental state examination; Tooth loss

\section{INTRODUCTION}

Dementia is emerging as a profound disease burden affecting mostly the geriatric population requiring proper monitoring and care throughout the world. As the care needs to be implemented over long time, it has the potential to impart huge burden to the family and caregivers, to impair the quality of life and economic productivity of the person as well as the family, and to jeopardize the society at large in the long run. ${ }^{1}$ The World Health Organization considers this to be a major concern with the current global load of around 50 million cases and addition of about 10 million new cases each year projecting the problem to be of substantial worry. ${ }^{2}$

Dementia is often preceded by a transitional stage of early decline in cognitive function more than that is expected for the age which mostly does not meet the diagnosis criteria of Alzheimer's disease or other forms of dementia. This situation, known as the mild cognitive impairment (MCI), 
is one important area to address as the definitive treatment of dementia remains non-rewarding despite improvement in the domains of imaging techniques, new pharmaceuticals, and the scope of rehabilitation of elderly persons. ${ }^{3}$ What most we can achieve effectively is to identify the preventable factors that can be associated with the advent of dementia and thus to delay the onset and the course progression of dementia to a large extent among the population. ${ }^{4}$ Apart from the well-established risk factors like aging, ${ }^{5}$ comorbidity, ${ }^{3}$ psychosocial factors, ${ }^{6}$ lifestyle issues, ${ }^{7}$ dietary deficiency, ${ }^{6,7}$ level of education, ${ }^{8}$ there lies factors such as oral hygiene and teeth loss that can harbinger such onset. ${ }^{9-11}$

Different evidences have been accumulating over the association of cognitive decline and dental hygiene in the forms of impaired chewing ability, periodontal disease ${ }^{10}$ and the number of lost teeth. ${ }^{9,11}$ Many possible etiological factors have been proposed to explain the association. Tooth loss can lead to the loss of trigeminal nerve conductivity to the periodontal mechanoreceptors rendering less involvement of the hippocampus in the registration of working memory. ${ }^{12}$ Another aspect remains in the hike of the systemic inflammatory burden with periodontal diseases associated with teeth loss. ${ }^{13}$ Neurodegenerative diseases such as Alzheimer's disease are notably associated with pro-inflammatory gene polymorphism and intensity of systemic inflammation. Although there are doubts about the direct causality over this association. ${ }^{14}$

In India, both the risk of cognitive decline and poor oral hygiene, and tooth loss is quite large. An estimated rise of 60 years and above aged population from $8 \%$ in 2010 to $19 \%$ in 2050 as forecasted by the United Nations Population Division is a worrisome indicator of the impending catastrophe. ${ }^{15} \mathrm{Few}$ prior Indian studies have researched on this topic from different regions of the country elaborating the situation. ${ }^{16,17}$ Prevention of later onset of dementia with identification at early stages has been of academic interest in India over the past decade due to its ever-enlarging social burden. ${ }^{18,19}$ Owing to scarcity of literature from the North East India in this topic, we tried to gather the information in this locality so that increased measures on different domains can be awarded as preventive modalities of prospective dementia.

\section{Aims and objectives}

To study the association between cognitive impairment in patients without registered diagnosis of dementia with tooth loss and chewing ability.

\section{MATERIALS AND METHODS}

This descriptive cross-sectional study was done in the North Bengal Medical College in collaboration with the
Department of Dentistry and Psychiatry. The tertiary care center is situated in the northern part of West Bengal catering a large heterogeneous population from the neighboring states and countries as well. In our study, the patients presented at the Dental outpatient department (OPD) were screened for $1 \frac{1 / 2}{2}$ year from January 2020 to June 2021. The eligible patients with a basic understanding of English, aged 60 years and above who presented with tooth loss at the Dental OPD were taken into study with written consent as per World Medical Association Declaration of Helsinki. After detailed dental examination including registration of number of teeth, tooth implant, third molar eruption status and subjective chewing capacity as normal or impaired on the basis of normal dietary consumption done by senior faculty, the patients were assessed at the Psychiatry OPD by two Psychiatrists separately. Patients with established Dementia, Cerebrovascular accidents, other neurodegenerative diseases, co-occurrence of other periodontal diseases, and those showing symptoms of Psychiatric illness as per mini international neuropsychiatric interview ${ }^{20}$ were excluded from the study. Eligible patients were assessed by the minimental state examination (MMSE) ${ }^{21}$ with a cut off $<25$ and the clock drawing test (CDT) ${ }^{22}$ with a cut off $<8$ as set for the presence of cognitive impairment and were scored accordingly. Detail data including marital status, education, occupation status, monthly income, socio-economic status, and presence of non-communicable chronic diseases such as diabetes mellitus, hypothyroidism, and hypertension were also taken into account using a semi-structured sociodemographic datasheet.

\section{Statistical analysis}

Among the data collected, continuous variables were assessed with mean and standard deviation calculation and specific variable frequency was also calculated. The qualitative data were compared with Chi-square test. Interrelation of age, chewing capacity, lost teeth variation, MMSE score, and Clock draw test score was assessed with Pearson's and Spearman's correlation. $\mathrm{P}<0.05$ was set to assert statistical significance. IBM Statistical Package for the Social Sciences Statistical software for Windows version 21.0 (IBM Corp., Armonk, N.Y., USA) was used to carry out the analysis.

\section{RESULTS}

Among the 96 participants included in the study, 77 (80.2\%) were male, and rest $21(19.8 \%)$ female. The mean age of the population was $68.30 \pm 6.28$ years. We have $52(54.2 \%)$ patients belonging to the age group of 60-69 years, $37(38.5 \%)$ of $70-79$ years group, and only $7(7.3 \%)$ patients of more than 80 years. Most of the participants were from semi-urban background (50\%), having above matriculation education (52.1\%) and married persons (86.5\%) outnumber 
the widowers $(13.5 \%)$ to a great extent. The average monthly income was diverse with a range of Rs. 100-7000/month (Median Rs. 3000/month). The dental examination of the patients found that $70(72.92 \%)$ patients had lost more than 20 teeth while presenting and the remaining $26(27.08 \%)$ patients had teeth number between 10 and 20 . The chewing capacity was reported to be impaired in 77 patients $(80.21 \%)$.

Upon evaluation $60(62.5 \%)$ patients showed cognitive decline with MMSE score <25. It was significantly more in females $(\mathrm{P}=0.029)$ and those with normal chewing capacity $(\mathrm{P}=0.003)$ as shown in Table 1a. On CDT 36 patients $(37.5 \%)$ showed cognitive deterioration as per the test cut-off value. The test value was significantly lower in $\geq 80$ years age group $(\mathrm{P}=0.009)$, people of rural background $(\mathrm{P}=0.033)$ and lower-income group $(\mathrm{P}=0.001)$ as shown in Table 1b. Comorbid chronic medical conditions like diabetes or hypertension were found to lack statistical significance among those groups.

We assessed the correlation of the test variables like the number of teeth lost and the number of teeth currently

\begin{tabular}{|c|c|c|c|c|}
\hline $\begin{array}{l}\text { Socio } \\
\text {-demographic } \\
\text { variables }\end{array}$ & $\begin{array}{l}\text { Cognitive } \\
\text { decline } \\
\text { (MMSE<25) }\end{array}$ & $\begin{array}{c}\text { Cognitive } \\
\text { normalcy } \\
\text { (MMSE } \geq 25 \text { ) }\end{array}$ & $x^{2}$ & P-value \\
\hline \multicolumn{5}{|l|}{ Age } \\
\hline $60-69$ & 29 & 23 & 4.898 & 0.086 \\
\hline $70-79$ & 28 & 9 & & \\
\hline$\geq 80$ & 3 & 4 & & \\
\hline \multicolumn{5}{|l|}{ Gender } \\
\hline Male & 44 & 33 & 4.764 & $0.029^{*}$ \\
\hline Female & 16 & 3 & & \\
\hline \multicolumn{5}{|l|}{ Marital status } \\
\hline Married & 52 & 31 & 0.006 & 0.939 \\
\hline Widowed & 8 & 5 & & \\
\hline \multicolumn{5}{|l|}{ Habitat } \\
\hline Urban & 18 & 12 & 0.184 & 0.912 \\
\hline Semi-urban & 31 & 17 & & \\
\hline Rural & 11 & 7 & & \\
\hline \multicolumn{5}{|l|}{ Education } \\
\hline$<$ Matric & 31 & 15 & 0.902 & 0.342 \\
\hline >Matric & 29 & 21 & & \\
\hline \multicolumn{5}{|l|}{$\begin{array}{l}\text { Income per } \\
\text { month }\end{array}$} \\
\hline$<3000$ & 27 & 20 & 1.003 & 0.317 \\
\hline$\geq 3000$ & 33 & 16 & & \\
\hline \multicolumn{5}{|l|}{ Chewing ability } \\
\hline Impaired & 54 & 23 & 9.663 & $0.003^{*}$ \\
\hline Normal & 6 & 13 & & \\
\hline \multicolumn{5}{|l|}{ Diabetes } \\
\hline Present & 17 & 10 & 0.003 & 0.953 \\
\hline Absent & 43 & 26 & & \\
\hline \multicolumn{5}{|l|}{ Hypertension } \\
\hline Present & 19 & 20 & 3.527 & 0.060 \\
\hline Absent & 17 & 40 & & \\
\hline
\end{tabular}

present as well as variables like age and monthly income with both the cognitive tests viz. MMSE and CDT. As depicted in Table 2, age $(\mathrm{r}=-0.211)$ and number of teeth lost $(r=-0.46)$ were inversely correlated with the MMSE score, and monthly income $(\mathrm{r}=0.518)$ and number of teeth present $(\mathrm{r}=0.230)$ were significantly correlated with the CDT score. Chewing capacity was found to have significant correlation with the MMSE score $(\mathrm{P}=0.348)$, though same significance was not seen with the CDT score.

\section{DISCUSSION}

The study was a cross-sectional descriptive one done on the patients attending the hospital with tooth loss without documented diagnosis of dementia or any other neurodegenerative diseases. The purpose was to find the association between tooth loss, chewing ability, and cognitive decline in persons aged 60 years and above who attended the tertiary care hospital. We administered MMSE and CDT to assess the cognitive status.

\begin{tabular}{|c|c|c|c|c|}
\hline $\begin{array}{l}\text { Socio- } \\
\text { demographic } \\
\text { variables }\end{array}$ & $\begin{array}{l}\text { Cognitive } \\
\text { decline } \\
\text { (CDT<8) }\end{array}$ & $\begin{array}{c}\text { Cognitive } \\
\text { normalcy } \\
\text { (CDT } \geq 8)\end{array}$ & $x^{2}$ & P-value \\
\hline \multicolumn{5}{|l|}{ Age } \\
\hline $60-69$ & 16 & 36 & 9.531 & $0.009^{*}$ \\
\hline $70-79$ & 20 & 17 & & \\
\hline$\geq 80$ & 0 & 7 & & \\
\hline \multicolumn{5}{|l|}{ Gender } \\
\hline Male & 26 & 51 & 2.254 & 0.185 \\
\hline Female & 10 & 9 & & \\
\hline \multicolumn{5}{|l|}{ Marital status } \\
\hline Married & 29 & 54 & 1.661 & 0.226 \\
\hline Widowed & 7 & 6 & & \\
\hline \multicolumn{5}{|l|}{ Habitat } \\
\hline Urban & 7 & 23 & 6.850 & $0.033^{*}$ \\
\hline Semi-urban & 18 & 30 & & \\
\hline Rural & 11 & 7 & & \\
\hline \multicolumn{5}{|l|}{ Education } \\
\hline$<$ Matric & 21 & 25 & 2.512 & 0.141 \\
\hline >Matric & 15 & 35 & & \\
\hline \multicolumn{5}{|l|}{$\begin{array}{l}\text { Income per } \\
\text { month }\end{array}$} \\
\hline$<3000$ & 27 & 20 & 16.173 & $0.001^{*}$ \\
\hline$\geq 3000$ & 9 & 40 & & \\
\hline \multicolumn{5}{|l|}{ Chewing ability } \\
\hline Impaired & 31 & 46 & 1.264 & 0.302 \\
\hline Normal & 5 & 14 & & \\
\hline \multicolumn{5}{|l|}{ Diabetes } \\
\hline Present & 10 & 17 & 0.003 & 0.573 \\
\hline Absent & 26 & 43 & & \\
\hline \multicolumn{5}{|l|}{ Hypertension } \\
\hline Present & 19 & 20 & 3.512 & 0.086 \\
\hline Absent & 17 & 40 & & \\
\hline
\end{tabular}


Table 2: Correlation of the number of lost teeth and chewing ability with MMSE and Clock draw score

\begin{tabular}{|c|c|c|c|c|}
\hline \multirow[t]{2}{*}{ Variables } & \multicolumn{2}{|c|}{ MMSE score } & \multicolumn{2}{|c|}{ Clock draw score } \\
\hline & r/P-value & Significance (P-value) & r/P-value & Significance (P-value) \\
\hline Age & $-0.211^{*}$ & 0.039 & 0.085 & 0.408 \\
\hline Income per month & -0.029 & 0.779 & $0.518^{* *}$ & 0.001 \\
\hline Number of teeth lost & $-0.460^{\star *}$ & 0.001 & $-0.279^{\star *}$ & 0.006 \\
\hline Number of teeth present & $0.418^{* *}$ & 0.000 & $0.230^{*}$ & 0.024 \\
\hline Chewing ability & $0.348^{* *}$ & 0.001 & 0.163 & 0.111 \\
\hline
\end{tabular}

**Correlation is significant at the 0.01 level (2-tailed), *Correlation is significant at the 0.05 level (2-tailed), MMSE: Mini-mental state examination

The data showed a positive correlation of number of teeth present and the cognitive score as assessed by MMSE and CDT separately. Number of missing teeth was on steady increment with persons with relative cognitive deterioration. It was inversely correlated to both MMSE and CDT with statistical significance as shown in Table 2. Multiple prior studies concurred with the finding regarding the association of tooth loss and cognitive decline. ${ }^{9,11}$ The mechanism by which these two are related is a matter of debate as multiple possible etiologies are there. It is also debated that cognitive decline itself is a risk factor of tooth loss as persons with low cognitive ability often show neglect to personal hygiene of the denture and oral cavity as a whole leading to tooth loss. possibility of a two-way causation was highlighted in various prior studies. . $^{14,23,24}$ Also there is a chance of prior periodontal disease that lead to tooth loss. ${ }^{10}$ These types of infective periodontitis can have a propensity to induce systemic inflammatory response later leading to increase in pro-inflammatory mediator in brain accentuating the chance of immunemediated cognitive decay. ${ }^{25}$ Specifically pro-inflammatory biomarker like C-reactive protein is linked to activation of cerebral glial system rendering risk of developing MCI and Alzheimer's disease later on. ${ }^{13,26}$ Regarding Alzheimer's disease pathognomonic $A \beta$ plaque formation, the role of an oral cavity pathogen Porphyromonas gingivalis was put forward in certain theories as well. ${ }^{27}$ However the role is not established unanimously as few studies did not find such association between oral cavity infection and cognitive decline. $^{25}$

Keeping that in mind we considered persons with tooth loss without simultaneous history of periodontal infection. We found association between tooth loss and poor cognition nonetheless. This finding might adhere to the second explanation that tooth loss could decrease the surrounding mechanoreceptor sensitivity as well as disuse hyposensitivity of the chewing muscles to the hippocampus and cortical pyramidal cells in mammals. ${ }^{12,28}$ We considered the subjective chewing ability and its association with cognitive level as well which yielded significant positive correlation with the MMSE score though not much with the CDT score as shown in Table 2. There is a difference of opinion regarding this hypothesis as well due to the presence of many confounding factors such as age, socio-economic status. as mentioned in few prior studies. ${ }^{14,25}$

Regarding these factors, in our study, we found significant association between older age and CDT score as shown in Table 1b. Rural background and relative low income of the family also showed similar association with low CDT score (Table 1b). All three factors are hypothesized to render inadequate dietary supplements, poor self-care or delay in treatment-seeking resulting in such difference. ${ }^{5,25,29}$

Interestingly MMSE score decline was significantly associated with females (Table 1a) which was found in a few prior studies as well. ${ }^{16,25,30}$ Social status of women, less exposure to outer world, delay in treatment seeking, etc were put forward as possible etiological factors of such finding. ${ }^{25}$ Detail research with large population in a prospective manner can throw more light in this domain.

We have found in our study that chronic non-communicable diseases like diabetes or hypertension did not impart significant effect to the cognitive decline (Table $1 \mathrm{a}$ and $\mathrm{b}$ ). It was notwithstanding with previous studies that showed association between cardiovascular or diabetes mellitus with cognitive impairment. ${ }^{31,32}$ Possible reasons can be smaller sample size or different population dynamics. Broader population studies are of need to counter the question more efficiently.

Other possible factors like education or loss of spouse did not convey any significant difference in our study among the normal and low cognitive groups. The finding was not in parity with few similar studies. ${ }^{6,8}$ Wider population involving study in this area may be needed to put forward better explanation in this matter. Despite the possible presence of other confounding factors, many studies have tried to adjust their impact in search of association between tooth loss and poor cognition. Keeping in mind variables such as age, sex, socio-economic status, or ethnicity, a few of them have found significant association between tooth loss, chewing capacity, and cognitive function..$^{24,33}$ However this finding is also not unanimous as few studies have found no statistically significance between them as well. ${ }^{34}$ 
Our study was first of this kind from this North-Eastern Sub-Himalayan belt in India that connects the mainland with the North-Eastern region of the country with a large catchment area spreading across different states and ethnic belts as well as some neighboring countries. With detail socio-demographic profiling, objective assessment of dental and cognitive status, we are looking forward with the findings that can be the stepping stone for populationbased prospective study to throw light on the preventive aspect of cognitive impairment and dementia. This study albeit has certain limitations. Due to the cross-sectional design, possible etiological association between cognitive function and loss of teeth could not be ascertained. Detail metabolic profiling was lacking in patients with chronic non-communicable disorders. Factors such as social support system, caregiver efficiency, treatmentseeking infrastructure that could hamper the cognitive function assessment were beyond the scope of this study as well. Also throughout the period of study, owing to the COVID-19 pandemic, the attendance in the hospital OPD was much less leading to the lower sample size which was a restraint in this endeavor.

\section{Limitations of the study}

The cross sectional study design was a definite limitation of the study which hindered causal inference. Also, low sample size during the pandemic was a problem. Detail oral examination was a shortcoming as well. Larger prospective study is needed.

\section{CONCLUSION}

As we conclude, our study population showed a positive correlation between impaired cognition and the number of extracted tooth. With further study on wider and representative population, we hope to project the role of maintaining good oral hygiene and dental care as a possible preventive strategy among many others to combat the increased burden of cognitive impairment as well as dementia that is looming over our society.

\section{ACKNOWLEDGMENT}

We acknowledge Dr. Nirmal Kumar Bera, Professor and Head, Department of Psychiatry, North Bengal Medical College for his support and enthusiasm in this endeavor.

\section{REFERENCES}

1. Cao Q, Tan CC, Xu W, Hu H, Cao XP, Dong Q, et al. The prevalence of dementia: A systematic review and meta-analysis. J Alzheimers Dis. 2020;73(3):1157-1166.

https://doi.org/10.3233/jad-191092
2. World Health Organization. Dementia. Geneva, Switzerland: World Health Organization; 2020. Available from: https:// www.who.int/news-room/fact-sheets/detail/dementia [Last accessed on 2020 Sep 21].

3. Mohan D, lype T, Varghese S, Usha A and Mohan M. A crosssectional study to assess prevalence and factors associated with mild cognitive impairment among older adults in an urban area of Kerala, South India. BMJ Open. 2019;9(3):e025473.

https://doi.org/10.1136/bmjopen-2018-025473

4. Korczyn AD. Is dementia preventable? Dialogues Clin Neurosci. 2009;11(2):213-216.

https://doi.org/10.31887/DCNS.2009.11.2/adkorczyn

5. Afgin AE, Massarwa M, Schechtman E, Israeli-Korn SD, Strugatsky R, Abuful A, et al. High prevalence of mild cognitive impairment and Alzheimer's disease in Arabic villages in northern Israel: Impact of gender and education. J Alzheimers Dis. 2012;29(2):431-439. https://doi.org/10.3233/JAD-2011-111667

6. Marengoni A, Fratiglioni L, Bandinelli $S$ and Ferrucci $L$. Socioeconomic status during lifetime and cognitive impairment no-dementia in late life: The population-based aging in the Chianti area (InCHIANTI) Study. J Alzheimers Dis. 2011;24(3):559-568. https://doi.org/10.3233/JAD-2011-101863

7. Habib R, Nyberg L and Nilsson LG. Cognitive and non-cognitive factors contributing to the longitudinal identification of successful older adults in the Betula study. Neuropsychol Dev Cogn B Aging Neuropsychol Cogn. 2007;14(3):257-273. https://doi.org/10.1080/13825580600582412

8. Gerstorf D, Herlitz A and Smith J. Stability of sex differences in cognition in advanced old age: The role of education and attrition. J Gerontol B Psychol Sci Soc Sci. 2006;61(4):245-249. https://doi.org/10.1093/geronb/61.4.P245

9. Reyes-Ortiz CA, Luque JS, Eriksson CK and Soto L. Self reported tooth loss and cognitive function: Data from the Hispanic established populations for epidemiologic studies of the elderly (Hispanic EPESE). Colomb Med (Cali). 2013;44(3):139-145. https://doi.org/10.25100/cm.v44i3.1248

10. Naorungroj S, Schoenbach VJ, Wruck L, Mosley TH, Gottesman RF, Alonso A, et al. Tooth loss, periodontal disease, and cognitive decline in the Atherosclerosis risk in communities (ARIC) study. Community Dent Oral Epidemiol. 2015;43(1):47-57. https://doi.org/10.1111/cdoe.12128

11. Hansson P, Sunnegardh-Gronberg K, Bergdahl J, Bergdahl M, Nyberg $L$ and Nilsson LG. Relationship between natural teeth and memory in a healthy elderly population. Eur $\mathrm{J}$ Oral Sci. 2013;121(4):333-340.

https://doi.org/10.1111/eos.12060

12. Jacobs $R$ and van Steenberghe D. From osseoperception to implant-mediated sensory-motor interactions and related clinical implications. J Oral Rehabil. 2006;33(4):282-292.

https://doi.org/10.1111/j.1365-2842.2006.01621.x

13. Paraskevas $S$, Huizinga JD and Loos BG. A systematic review and meta-analyses on $\mathrm{C}$-reactive protein in relation to periodontitis. J Clin Periodontol. 2008;35(4):277-290. https://doi.org/10.1111/j.1600-051X.2007.01173.x

14. Borrell LN and Crawford ND. Socioeconomic position indicators and periodontitis: Examining the evidence. Periodontol 2000. 2012;58(1):69-83.

https://doi.org/10.1111/j.1600-0757.2011.00416.x

15. Population Reference Bureau, Today's Research on Aging. Vol. 25; 2012. p. 16. Available from: https://www.prb. org/todays-research-on-aging. [Last accessed on 2020 Sep 21]. 
16. Patil S, Patel S, Shivakumar KM and Hathiwala S. Relationship of tooth loss, impaired chewing ability, and cognitive impairment among the elderly of western Maharashtra, India. J Int Oral Health. 2018;10:172-175.

https://doi.org/10.4103/jioh.jioh_89_18

17. Ranjan R, Rout M, Mishra M and Kore SA. Tooth loss and dementia: An oro-neural connection. A cross-sectional study. J Indian Soc Periodontol. 2019;23(2):158-162.

https://doi.org/10.4103/jisp.jisp_430_18

18. Ghose S, Das S, Poria S and Das T. Short test of mental status in the detection of mild cognitive impairment in India. Indian J Psychiatry. 2019;61(2):184-191.

https://doi.org/10.4103/psychiatry.indianjpsychiatry_145_18

19. Tripathi R, Kumar K, Balachandar R, Marimuthu $P$, Varghese $M$, Bharath $S$, et al. Cognitive markers of mild cognitive impairment: An Indian experience. Ann Indian Acad Neurol. 2016;19(1):164.

https://doi.org/10.4103/0972-2327.175513

20. Sheehan DV, Lecrubier $Y$, Sheehan KH, Amorim P, Janavs J, Weiller E, et al. The mini-international neuropsychiatric interview (M.I.N.I.): The development and validation of a structured diagnostic psychiatric interview for DSM-IV and ICD-10. J Clin Psychiatry. 1998;59 Suppl 20:22-33;quiz 34-57.

21. Dellasega $C$, Morris D. The MMSE to assess the cognitive state of elders. Mini-mental state examination. J Neurosci Nurs. 1993;25(3):147-152.

https://doi.org/10.1097/01376517-199306000-00003

22. Yamamoto $S$, Mogi $N$, Umegaki $H$, Suzuki $Y$, Ando $F$, Shimokata $\mathrm{H}$, et al. The clock drawing test as a valid screening method for mild cognitive impairment. Dement Geriatr Cogn Disord. 2004;18(2):172-179.

https://doi.org/10.1159/000079198

23. Chalmers JM, Carter KD and Spencer AJ. Caries incidence and increments in community-living older adults with and without dementia. Gerodontology. 2002;19(2):80-94. https://doi.org/10.1111/j.1741-2358.2002.00080.x

24. Wu B, Plassman BL, Crout RJ and Liang J. Cognitive function and oral health among community-dwelling older adults. J Gerontol A Biol Sci Med Sci. 2008;63(5):495-500.

https://doi.org/10.1093/gerona/63.5.495

25. ALFotawi R, Alzahrani S, Alhefdhi R, Altamimi A, Alfadhel A, Alshareef $A$, et al. The relation between teeth loss and cognitive decline among Saudi population in the city of Riyadh: A pilot study. Saudi Dent J. 2020;32(5):232-241.

https://doi.org/10.1016/j.sdentj.2019.09.007
26. Batty GD, Li Q, Huxley R, Zoungas S, Taylor BA, Neal B, et al. Oral disease in relation to future risk of dementia and cognitive decline: Prospective cohort study based on the action in diabetes and vascular disease: Preterax and diamicron modifiedrelease controlled evaluation (ADVANCE) trial. Eur Psychiatry. 2013;28(1):49-52.

https://doi.org/10.1016/j.eurpsy.2011.07.005

27. Seraj Z, Al-Najjar D, Akl M, Aladle N, Altijani Y, Zaki A, et al. The effect of number of teeth and chewing ability on cognitive function of elderly in UAE: A pilot study. Int J Dent. 2017;2017:5732748. https://doi.org/10.1155/2017/5732748

28. Yamazaki K, Wakabayashi N, Kobayashi T and Suzuki T. Effect of tooth loss on spatial memory and trkB-mRNA levels in rats. Hippocampus. 2008;18(6):542-547. https://doi.org/10.1002/hipo.20440

29. Carlson MC, Helms MJ, Steffens DC, Burke JR, Potter GG and Plassman BL. Midlife activity predicts risk of dementia in older male twin pairs. Alzheimers Dement. 2008;4(5):324-331. https://doi.org/10.1016/j.jalz.2008.07.002

30. Altmann A, Tian L, Henderson VW, Greicius MD and Alzheimer's Disease Neuroimaging Initiative Investigators. Sex modifies the APOE-related risk of developing Alzheimer disease. Ann Neurol. 2014;75(4):563-573

https://doi.org/10.1002/ana.24135

31. Luchsinger JA, Tang MX, Stern $Y$, Shea $S$ and Mayeux R. Diabetes mellitus and risk of Alzheimer's disease and dementia with stroke in a multiethnic cohort. Am J Epidemiol. 2001;154(7):635-641.

https://doi.org/10.1093/aje/154.7.635

32. Pendlebury ST and Rothwell PM. Prevalence, incidence, and factors associated with pre-stroke and post-stroke dementia: A systematic review and meta-analysis. Lancet Neurol. 2009;8(11):1006-1018. https://doi.org/10.1016/S1474-4422(09)70236-4

33. Okamoto N, Morikawa M, Okamoto K, Habu N, Iwamoto J, Tomioka K, et al. Relationship of tooth loss to mild memory impairment and cognitive impairment: Findings from the fujiwarakyo study. Behav Brain Funct. 2010;6(1):77. https://doi.org/10.1186/1744-9081-6-77

34. Lexomboon D, Trulsson M, Wardh I and Parker MG. Chewing ability and tooth loss: Association with cognitive impairment in an elderly population study. J Am Geriatr Soc. 2012;60(10):1951-1956. https://doi.org/10.1111/j.1532-5415.2012.04154.x

\footnotetext{
Authors Contribution:

UM- Concept and design of the study, revision of the manuscript; IB- Statistical analysis and data interpretation, review of literature; AKL- First draft of the manuscript, co-ordination, result interpretation; SRB- Data collection, clinical examination, revision of the manuscript; PKR-Design of the study, co-ordination, result interpretation

Work attributed to:

North Bengal Medical College, Sushrutanagar, Darjeeling, West Bengal, India

Orcid ID:

Dr. Uttam Majumder - it https://orcid.org/0000-0003-2416-6307

Dr. Iti Baidya - il https://orcid.org/0000-0003-2000-7253

Dr. Avik Kumar Layek - (D) https://orcid.org/0000-0002-5400-8230

Dr. Sampa Ray Bhattacharya - (1) https://orcid.org/0000-0001-8654-1307

Dr. Pradip Kumar Ray - (1) https://orcid.org/0000-0003-1592-9181

Source of Funding: None, Conflicts of Interest: None.
} 